\title{
Bacteroides massiliensis sp. nov., isolated from blood culture of a newborn
}

\author{
Correspondence \\ Didier Raoult \\ didier.raoult@medecine. \\ univ-mrs.fr
}

\author{
Lukas Fenner, ${ }^{1}$ Véronique Roux, ${ }^{2}$ Marie-Noëlle Mallet ${ }^{2}$ and Didier Raoult ${ }^{2}$ \\ 1 Unité des Rickettsies, CNRS UPRESA 6020, Faculté de Médecine, Université de la \\ Méditerrannée, 27 Boulevard Jean Moulin, 13385 Marseille Cedex 05, France \\ ${ }^{2}$ Laboratoire de Bactériologie - Virologie, Hôpital de la Timone, CNRS UMR 6020, IFR48, \\ 264 rue Saint-Pierre, 13385 Marseille, Cedex 05, France
}

Gene comparison studies and phylogenetic analysis including $16 \mathrm{~S}$ rRNA sequencing have led to the identification of new genera and species and the reclassification of numerous bacterial species, often leading to changes in the nomenclature and classification of anaerobic bacteria (JousimiesSomer \& Summanen, 2002). Anaerobic bacteria play an important role in the regulation of the immune system or nutrient processing, for example, as part of the human gut microbial community (Hooper \& Gordon, 2001). On the other hand, they may be causal agents in human infections (Finegold, 1979). Anaerobic organisms account for about $4 \%$ of bacteraemias $(0 \cdot 5-9 \%)$, depending on geographical location, hospital patient demographics and patient age. Species of the Bacteroides group account for over $50 \%$ of anaerobic bacteraemias (Goldstein, 1996). The incidence of recovery of anaerobes in neonatal bacteraemia varies, according to different studies, between 1.8 and $12.5 \%$ (Brook, 1990). Predisposing factors are perinatal maternal complications such as premature rupture of membranes, prematurity and necrotizing enterocolitis. Here we report a novel species within the genus Bacteroides isolated from blood culture of a newborn.

\section{Isolation and characterization of the strain}

In May 2002, a healthy male baby was born at term by vaginal delivery after an uncomplicated pregnancy. His mother was a 31-year-old primapara. The only complication was a pre-term rupture of amniotic membrane (more than

Published online ahead of print on 21 January 2005 as DOI 10.1099/ ijs.0.63350-0.

The GenBank/EMBL/DDBJ accession number for the 16S rRNA gene sequence of Bacteroides massiliensis B84634 ${ }^{\top}$ is $A Y 126616$.

A table of antimicrobial susceptibility data is available as supplementary material in IJSEM Online.
$12 \mathrm{~h}$ before delivery). Subsequently, the mother developed fever and was treated with antibiotics. Microbiological examinations (blood culture, amniotic fluid and placenta) were found to be negative. On the first day, a blood culture of the newborn was routinely ordered and a Gram-negative bacillus was isolated in the bacteriology laboratory of the Timone Hospital. Strain B84634 ${ }^{\mathrm{T}}$ was assigned to the genus Bacteroides, based on $16 \mathrm{~S}$ rRNA gene sequencing. The baby had no clinical signs of a systemic infection and C-protein reaction was recorded as $1 \mathrm{mg} \mathrm{l}^{-1}$. Due to the pre-term rupture of amniotic membrane, the baby received prophylactic antibiotic therapy. Microbial invasion of the amniotic cavity in women with premature rupture of membranes occurs in one-third of patients, with Ureaplasma urealyticum and anaerobic bacteria such as Bacteroides fragilis being the most commonly isolated bacteria (Romero et al., 1992). Thus, transfer of Bacteroides sp. $\mathrm{B} 84634^{\mathrm{T}}$ from mother to child seems possible even if the isolate had no clinical significance in this case. However, antimicrobial susceptibility was determined according to the National Committee for Clinical Laboratory Standards (NCCLS) criteria and is presented in the Supplementary Table in IJSEM Online; these data are in accordance with those obtained for the other Bacteroides species. Strain $\mathrm{B} 84634^{\mathrm{T}}$ produced $\beta$-lactamase as determined by the cefinase test (Becton Dickinson).

Surface colonies of strain $\mathrm{B} 84634^{\mathrm{T}}$ on sheep blood agar plates after $48 \mathrm{~h}$ were $1-2 \mathrm{~mm}$ in diameter, circular, white-greyish, translucent, raised and convex. Growth and haemolytic activity were tested at $37^{\circ} \mathrm{C}$ on Columbia agar with $5 \%$ sheep blood (bioMérieux). There was no haemolysis on sheep blood agar. Growth was tested in anaerobic and microaerophilic atmospheres which were created using GENbag anaer and GENbag microaer (bioMérieux), respectively. Growth was also tested in 
presence of air or $5 \% \mathrm{CO}_{2}$. Different temperatures $(25,30$, 33 and $37^{\circ} \mathrm{C}$ ) were tested. Optimum growth was obtained at $37^{\circ} \mathrm{C}$ and the bacteria were strictly anaerobic.

The size of the bacterial cells grown for $48 \mathrm{~h}$ was examined by transmission electron microscopy. Bacterial suspension was pre-fixed in $5 \%(\mathrm{v} / \mathrm{v})$ glutaraldehyde (Sigma) in phosphate buffer (Gibco) for at least $1 \mathrm{~h}$ at room temperature, washed in the same buffer and stained with $1 \%(\mathrm{w} / \mathrm{v})$ phosphotungstic acid. The samples were examined on a Morgagni 268D (Philips) electron microscope at an operating voltage of $60 \mathrm{kV}$. Organisms with the typical cell structure of Gram-negative rods were noted and were $0 \cdot 8-1 \cdot 4 \mu \mathrm{m}$ wide and $2 \cdot 1-3 \cdot 9 \mu \mathrm{m}$ long, and usually occurred singly. Bile resistance was tested by growing the bacteria on peptone/yeast extract/glucose agar plates supplemented with $2 \%$ dehydrated gall salt (w/v, bile sac powder; MP Biomedicals) equivalent to $20 \%(\mathrm{v} / \mathrm{v})$ bile. Antibiotic resistance to $5 \mu \mathrm{g}$ vancomycin $\mathrm{ml}^{-1}, 1000 \mu \mathrm{g}$ kanamycin $\mathrm{ml}^{-1}$ and $10 \mu \mathrm{g}$ colistin $\mathrm{ml}^{-1}$ was tested in thioglycollate with resazurin broth (bioMérieux). Anaerobic atmosphere was created by the addition of $2 \mathrm{ml}$ paraffin oil. Strain B84634 ${ }^{\mathrm{T}}$ exhibited the characteristics of the $B$. fragilis group, they are bile resistant and share common antibiotic resistance patterns. Catalase activity was determined with the ID colour Catalase test kit (bioMérieux). Other biochemical tests were performed by inoculation of API 20A and API $32 \mathrm{~A}$ strips (bioMérieux) according to the manufacturer's instructions and incubation at $37^{\circ} \mathrm{C}$. API 50CH strips were also used. An anaerobic atmosphere was created by adding paraffin oil before incubation at $37^{\circ} \mathrm{C}$. Diagnostic traits are specified in Table 1. Bacteroides vulgatus CIP $103714^{\mathrm{T}}$ was purchased from the Collection de l'Institut Pasteur (Paris, France) and used as reference strain.

Preparation and determination of cellular fatty acids were carried out by following the procedures given for the Sherlock Microbial Identification System (MIDI). The major cellular fatty acids were anteiso-branched $C_{15: 0}$ $(31 \cdot 1 \%)$ as described for the other Bacteroides species. Analysis of DNA G $+\mathrm{C}$ content was performed by HPLC as described previously (La Scola et al., 2003) and was recorded as $49 \mathrm{~mol} \%$.

Bacterial DNA was extracted by using the QIAmp DNA Mini kit (Qiagen) as described by the manufacturer. The 16S rRNA gene was amplified by PCR using the universal primer pair fD1 and rp2 (Weisburg et al., 1991). PCR products were purified using MultiScreen PCR (Millipore) and sequencing reactions were carried out using a DNA sequencing kit (BigDye Terminator Cycle Sequencing v2.0 Ready Reactions; PE Biosystems) as described by the manufacturer. Sequencing products were purified and electrophoresis was performed with the 3100 Genetic Analyzer (Applied Biosystems). The 16S rRNA gene sequences were aligned using the multisequence alignment program CLUSTAL_X (1.8). The phylogenetic relationships between the representatives of the genus Bacteroides and closely related genera were determined using MEGA version
Table 1. Diagnostic traits of $B$. massiliensis $B 84634^{\top}$ and its closest relative, B. vulgatus CIP $103714^{\top}$

All characters tested are listed in the description of B. massiliensis sp. nov. and were identical for the two species. V, Variable.

\begin{tabular}{|c|c|c|}
\hline Characteristic & $\mathrm{B} 84634^{\mathrm{T}}$ & CIP $103714^{\mathrm{T}}$ \\
\hline Bile resistance & + & + \\
\hline Aesculin hydrolysis & + & - \\
\hline \multicolumn{3}{|l|}{ Acid production from: } \\
\hline Arabinose & - & + \\
\hline Fucose & - & + \\
\hline Rhamnose & - & + \\
\hline Ribose & - & + \\
\hline Sorbitol & $\mathrm{V}$ & - \\
\hline Xylose & - & + \\
\hline \multicolumn{3}{|l|}{ Enzymic activity } \\
\hline Catalase & - & - \\
\hline$\alpha$-Arabinosidase & - & + \\
\hline Glutamic acid decarboxylase & - & + \\
\hline Leucine arylamidase & + & - \\
\hline Glycine arylamidase & - & + \\
\hline Glutamyl glutamic acid arylamidase & - & + \\
\hline
\end{tabular}

2.1 (Kumar et al., 2001). Distance matrices were determined following the assumptions described by Kimura (1980). These matrices were used to elaborate dendrograms using the neighbour-joining method (Saitou \& Nei, 1987). The maximum-parsimony algorithm was also used to infer phylogenetic analysis. A bootstrap analysis was performed to investigate the stability of the trees obtained. Bootstrap values were obtained for a consensus tree based on 100 randomly generated trees. The tree organization was the same with the two methods. Strain $\mathrm{B} 84634^{\mathrm{T}}$ grouped with B. vulgatus (bootstrap value $100 \%$, Fig. 1). The percentage similarity between $16 \mathrm{~S}$ rRNA gene sequences was determined using NALIGN in the PC/GENE software package (IntelliGenetics). Sequence similarity between B. vulgatus and strain $\mathrm{B} 84634^{\mathrm{T}}$ was $92 \cdot 8 \%$ and lower sequence similarity values were found with all species of the genus Bacteroides whose names have been validly published.

Based on results described above, we propose the name of Bacteroides massiliensis sp. nov. for the described bacterium, with $\mathrm{B} 84634^{\mathrm{T}}$ being the type strain.

\section{Description of Bacteroides massiliensis sp. nov.}

Bacteroides massiliensis (mas.si.li.en'sis. L. adj. massiliensis of Massilia, the ancient Greek and Roman name for Marseille, France, where the type strain was isolated).

Cells are strictly anaerobic, non-spore-forming, non-motile, Gram-negative, straight rods that are $0 \cdot 8-1 \cdot 4 \mu \mathrm{m}$ wide and $2 \cdot 1-3 \cdot 9 \mu \mathrm{m}$ long, and which usually occur singly. Surface colonies on sheep blood agar plates after 2 days are $1-2 \mathrm{~mm}$ in diameter, circular, white-greyish, translucent, raised and convex. No haemolysis on sheep blood agar. Optimum 


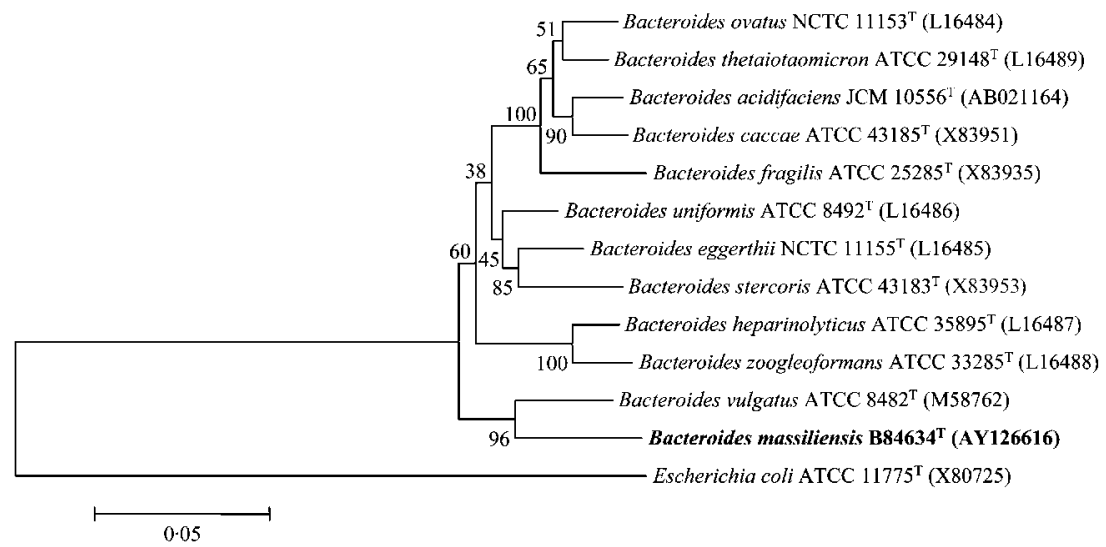

Fig. 1. Phylogenetic tree of bacteria belonging to the genus Bacteroides inferred from comparison of the 16S rRNA gene sequences (1365 nucleotides). Nucleotide accession numbers for the sequences used to construct this dendrogram are given in parentheses. Bar, 0.05 nucleotide change per nucleotide position. Escherichia coli was used as the outgroup. growth temperature is $37^{\circ} \mathrm{C}$, but growth is observed at $25-42^{\circ} \mathrm{C}$. Grows in the presence of bile and is resistant to $5 \mu \mathrm{g}$ vancomycin $\mathrm{ml}^{-1}, 1000 \mu \mathrm{g}$ kanamycin $\mathrm{ml}^{-1}$ and $10 \mu \mathrm{g}$ colistin $\mathrm{ml}^{-1}$. Indole-negative and catalase-negative. Does not reduce nitrate to nitrite. Gelatin is not liquefied. Aesculin is hydrolysed. Using API ID 32A (bioMérieux), activities of $\alpha$ - and $\beta$-galactosidase, $\alpha$-glucosidase, $N$-acetyl$\beta$-glucosaminidase, $\alpha$-fucosidase, alkaline phosphatase, leucyl glycine arylamidase, leucine arylamidase and alanine arylamidase are detected. No activity is detected for urease, arginine dihydrolase, $\beta$-galactosidase-6-phosphatase, $\beta$ glucosidase, $\alpha$-arabinosidase, $\beta$-glucuronidase, glutamic acid decarboxylase, arginine arylamidase, proline arylamidase, phenylalanine arylamidase, pyroglutamic acid arylamidase, tyrosine arylamidase, glycine arylamidase, histidine arylamidase, glutamyl glutamic acid arylamidase or serine arylamidase. The following sugars are fermented: starch, aesculin, fructose, galactose, glucose, $\mathrm{N}$-acetylglucosamine, lactose, maltose, mannose, melibiose, raffinose, saccharose and sucrose. Fermentation of sorbitol is variable. The following sugars are not fermented: amygdalin, arabinose, cellobiose, dulcitol, erythritol, fucose, gluconate, glycerol, glycogen, inositol, inulin, mannitol, melezitose, methyl $\alpha$-D-glucoside, rhamnose, ribose, salicin, sorbitol, sorbose, trehalose, xylitol and xylose. The DNA G + C content is $49 \mathrm{~mol} \%$. The major cellular fatty acid is anteiso-branched $\mathrm{C}_{15: 0}$.

The type strain, which was isolated from human blood culture, is $\mathrm{B} 84634^{\mathrm{T}}$; it has been deposited in the Collection de l'Institut Pasteur, Paris, France, as CIP $107942^{\mathrm{T}}$ and in the Collection of the University of Göteborg, Sweden, as CCUG $48901^{\mathrm{T}}$.

\section{Acknowledgements}

We are grateful to Nicolas Aldrovandi for his technical assistance in electronic microscopy, and to Kent Molin (University of Göteborg,
Sweden) for his technical assistance in determining cellular fatty acid composition.

\section{References}

Brook, I. (1990). Bacteremia due to anaerobic bacteria in newborns. J Perinatol 10, 351-356.

Finegold, S. M. (1979). Taxonomy, enzymes, and clinical relevance of anaerobic bacteria. Rev Infect Dis 1, 248-253.

Goldstein, E. J. C. (1996). Anaerobic bacteremia. Clin Infect Dis 23, S97-S101.

Hooper, L. V. \& Gordon, J. I. (2001). Commensal host-bacterial relationships in the gut. Science 292, 1115-1118.

Jousimies-Somer, H. \& Summanen, P. (2002). Recent taxonomic changes and terminology update of clinically significant anaerobic gram-negative bacteria (excluding spirochetes). Clin Infect Dis 35, S17-S21.

Kimura, M. (1980). A simple method for estimating evolutionary rates of base substitutions through comparative studies of nucleotide sequences. J Mol Evol 16, 111-120.

Kumar, S., Tamura, K., Jakobsen, I. B. \& Nei, M. (2001). MEGA2: molecular evolutionary genetics analysis software. Bioinformatics 17, 1244-1245.

La Scola, B., Mallet, M. N., Grimont, P. A. D. \& Raoult, D. (2003). Bosea eneae sp. nov., Bosea massiliensis sp. nov. and Bosea vestrisii sp. nov., isolated from hospital water supplies, and emendation of the genus Bosea (Das et al. 1996). Int J Syst Evol Microbiol 53, $15-20$.

Romero, R., Mazor, M., Corrotti, R. \& 7 other authors (1992). Infection and labor. VII. Microbial invasion of the amniotic cavity in spontaneous rupture of membranes at term. Am J Obstet Gynecol 166, 129-133.

Saitou, N. \& Nei, M. (1987). The neighbour-joining method: a new method for reconstructing phylogenetic trees. Mol Biol Evol 4, 406-425.

Weisburg, W. G., Barns, S. M., Pelletier, D. A. \& Lane, D. J. (1991). $16 \mathrm{~S}$ ribosomal DNA amplification for phylogenetic study. J Bacteriol 173, 697-703. 